\title{
LEO Baby Stent Use following Balloon-Assisted Coiling: Single- and Dual-Stent Technique_-Immediate and Midterm Results of 29 Consecutive Patients
}

\author{
P. Machi, V. Costalat, K. Lobotesis, C. Ruiz, Y.B. Cheikh, O. Eker, G. Gascou, F. Danière, C. Riquelme, and A. Bonafé
}

\begin{abstract}
BACKGROUND AND PURPOSE: We report our preliminary results in terms of safety and efficacy in using the low-profile LEO Baby stent for the treatment of large-neck and complex intracranial aneurysms with balloon-then-stent-assisted coiling and single- or dual-stentassisted coiling.
\end{abstract}

MATERIALS AND METHODS: Clinical and radiologic data of all consecutive patients treated at our institution from September 2012 to October 2013 for an intracranial aneurysm by using a LEO Baby stent were retrospectively analyzed. Immediate and midterm clinical and anatomic follow-up of each patient is reported.

RESULTS: Twenty-nine patients with 29 aneurysms were treated with LEO Baby stents at our institution. The mean age of patients was 48 years; 20 patients were women (71\%). One patient was treated in the acute phase of a subarachnoid hemorrhage. In 8 procedures, a double-lumen-catheter balloon was used for balloon-then-stent-assisted coiling. In 3 cases, a LEO Baby stent was used in a Y-, T-, and telescopic dual-stent configuration. In 18 cases, a single LEO Baby stent was used. In 2 cases, technical failure to deploy the stent resulted in acute parent artery thrombosis. In 3 further cases, thromboembolic complications occurred intraoperatively. MR imaging and angiographic midterm follow-up showed complete aneurysm occlusion for $96 \%$ of the followed patients (27/29). Clinical outcome was favorable for all patients followed up.

CONCLUSIONS: Results obtained in our study by using the LEO Baby stent for balloon-then-stent and single- or dual-stent-assisted coiling of complex and distally located intracranial aneurysms are encouraging. Incomplete or inadequate opening of the device is a potential cause of laminar blood flow alteration and thrombus formation.

ABBREVIATIONS: ACA = anterior cerebral artery; AcomA = anterior communicating artery; LBS = LEO Baby stent

$\mathbf{T}$ he results of endovascular treatment of wide-neck and complex intracranial aneurysms have improved following the introduction of balloon remodeling and stent-assisted coiling. ${ }^{1-6}$ Theoretically, intracranial stents act as a scaffold to maintain the coil mass within the aneurysmal sac, allowing higher packing density. This leads to a reduction of the blood flow into the aneurysmal sac while diverting it toward the parent vessel and provides support for the neointima growth across the neck. ${ }^{7,8}$ The LEO Baby stent (LBS; Balt Extrusion, Montmorency, France) is a new self-expandable stent with 16 nitinol wires (2 of which are ra-

Received December 2, 2014; accepted after revision March 19, 2015.

From the Centre Hospitalier Universitaire Gui de Chauliac (P.M., V.C., C.R., Y.B.C., O.E., G.G., F.D., C.R., A.B.), Montpellier, France; and Imperial College Healthcare (K.L.), London, UK.

Please address correspondence to Paolo Machi, MD, Centre Hospitalier Universitaire Gui de Chauliac, 80 Ave Augustine Fliche 34000 Montpellier, France; e-mail: paolo.machi@gmail.com

http://dx.doi.org/10.3174/ajnr.A4413 diopaque). This braided microstent can be delivered through a 0.0165-inch microcatheter or a dual-lumen balloon catheter system (Scepter XC; MicroVention, Tustin, California) and deployed within arteries with diameters ranging from 1.5 to 3.1 $\mathrm{mm}$. In the present study, we report our preliminary results in terms of safety and efficacy by using the LBS for the treatment of large-neck and complex intracranial aneurysms with balloon-then-stent-assisted coiling and single- or dual-stent-assisted coiling.

\section{MATERIALS AND METHODS \\ Patient Sample}

Clinical and radiologic data of all consecutive patients treated at our institution from September 2012 to October 2013 for an intracranial aneurysm by stent-assisted coiling by using LBSs were retrospectively analyzed. This study followed institutional review board approval. Written informed consent was obtained from every patient before treatment. 


\begin{tabular}{|c|c|c|c|c|c|}
\hline Pt & Aneurysm Location & Procedural Technique & Adverse Events & Clinical Outcome & Aneurysm Cure \\
\hline 1 & AcomA & Single stent & Yes & Favorable & Yes \\
\hline 2 & BA & Single stent & No & Favorable & Yes \\
\hline 3 & MCA & Dual Y-stents & No & Favorable & No \\
\hline 4 & ICA bifurcation & Single stent & Yes & Favorable & Yes \\
\hline 5 & $\mathrm{ACA}(\mathrm{Al})$ & Single stent & No & Favorable & Yes \\
\hline 6 & MCA & Single stent & No & Favorable & Yes \\
\hline $6 \mathrm{bis}^{\mathrm{a}}$ & MCA & Dual T-stents & No & Favorable & Yes \\
\hline 7 & $\mathrm{ACA}(\mathrm{Al})$ & Telescopic & Yes & Unfavorable & \\
\hline 8 & MCA & Balloon/stent & No & Favorable & Yes \\
\hline 9 & MCA & Single stent & No & Favorable & Yes \\
\hline 10 & MCA & Single stent & Yes & Favorable & Yes \\
\hline 11 & Callosomarginal & Balloon/stent & No & Favorable & Yes \\
\hline 12 & $\mathrm{ACA}(\mathrm{Al})$ & Dual T-stents & No & Favorable & Yes \\
\hline 13 & MCA & Balloon/stent & No & Favorable & Yes \\
\hline 14 & AcomA & Single stent & Yes & Unfavorable & \\
\hline 15 & MCA & Balloon/stent & No & Favorable & Yes \\
\hline 16 & MCA & Single stent & No & Favorable & Yes \\
\hline 17 & AcomA & Single stent & No & Favorable & Yes \\
\hline 18 & MCA & Single stent & No & Favorable & Yes \\
\hline 19 & AcomA & Single stent & No & Favorable & Yes \\
\hline 20 & AcomA & Single stent & No & Favorable & Yes \\
\hline 21 & AcomA & Single stent & No & Favorable & Yes \\
\hline 22 & PICA & Single stent & No & Favorable & Yes \\
\hline 23 & AcomA & Single stent & No & Favorable & Yes \\
\hline 24 & MCA & Balloon/stent & No & Favorable & Yes \\
\hline 25 & BA & Single stent & No & Favorable & Yes \\
\hline 26 & MCA & Balloon/stent & No & Favorable & Yes \\
\hline 27 & AcomA & Balloon/tent & No & Favorable & Yes \\
\hline 28 & MCA & Balloon/stent & No & Favorable & Yes \\
\hline 29 & $\mathrm{ACA}(\mathrm{Al})$ & Single stent & No & Favorable & Yes \\
\hline
\end{tabular}

Note:-Pt indicates patient; BA, basilar artery.

${ }^{a}$ Retreatment of patient 6 for the second time with a LEO baby stent.

\section{Medications}

Patients treated for an unruptured aneurysm were premedicated the day before the procedure with a loading dose of 300 mg of clopidogrel. Resistance to clopidogrel was tested in the angiosuite by using a VerifyNow P2Y12 assay (Accumetrics, San Diego, California) just before the procedure. The day after the procedure, a dual-antiplatelet regimen was introduced for 3 months (75 mg clopidogrel and $75 \mathrm{mg}$ aspirin, once daily); thereafter mono-antiplatelet therapy was maintained with aspirin for an additional 3 months. Patients treated in the acute phase of a subarachnoid hemorrhage were not premedicated and received an intravenous bolus of aspirin or anti-glycoprotein IIb/IIIa intraoperatively after LBS placement. All procedures were performed in patients on systemic anticoagulation with an activated clotting time maintained between 200 and 300 seconds. At the end of the procedure, the systemic anticoagulation was not continued.

\section{Techniques}

All procedures were performed with the patient under general anesthesia and by a senior interventional neuroradiologist with prior experience in intracranial stent placement. Depending on the technique of choice, a single or bilateral femoral artery approach was performed. A 6F or 7F guide catheter was placed proximally in the aneurysm parent artery (internal carotid or vertebral artery); a second guide catheter was placed in the contralateral corresponding artery; the contralateral catheter was not used systematically. Patients in this series were treated with different tech- niques: single-stent or dual-stent-assisted coiling or remodelling balloon-assisted coiling followed by parent artery stent placement. Moreover, in 1 case of a ruptured blister aneurysm, 2 LBSs were used in a telescopic configuration to produce a flow-diverting effect without adjunctive aneurysm coiling. In cases of dualstent-assisted coiling, the LBSs were deployed in a Y-or T-configuration. In 3 cases of dual-stent placement, a Neuroform EZ stent system (Stryker Neurovascular, Fremont, California) was used in combination with an LBS.

\section{Radiologic and Clinical Follow-Up}

All patients were scheduled for an MR imaging/MRA follow-up at 6 months and conventional DSA at 12 months. The MR imaging follow-up consisted of structural imaging and time-of-flight MR angiography performed by using a 1.5T MR imaging scanner (Avanto; Siemens, Erlangen, Germany). Clinical outcomes were assessed at the time of the radiologic follow-up by using the modified Rankin Scale. An mRS of $\leq 2$ was considered a good outcome.

\section{RESULTS}

\section{Patient Sample}

Between September 2012 and October 2013, 41 patients were treated at our institution endovascularly by stent-assisted coiling. Among them, 29 patients with 29 aneurysms were treated with LBSs (Table). Patients were selected for the specific treatment because of either the small parent vessel diameter or the need for 
delivery of the stent via a "low-profile" microcatheter or balloon. One patient was treated twice for the same aneurysm (patient 6). The mean age of patients was 48 years (range, 23-68 years), and 20 patients were women $(71 \%)$. One patient was treated in the acute phase of a subarachnoid hemorrhage due to a blister aneurysm. In 11 patients, an LBS was deployed for retreatment of an aneurysm previously treated endovascularly (10 cases) or surgically ( 1 case).

\section{Aneurysm Location}

Twelve aneurysms were located at the MCA bifurcation (1 treated twice), 8 were located at the anterior communicating artery (AcomA), 4 were located on the anterior cerebral artery (ACA, A1 segment), 1 was located at the pericallosal/callosomarginal artery bifurcation, 1 was located at the ICA bifurcation, 2 arose from the top of the basilar artery, and 1 was located on the proximal portion of the posterior inferior cerebellar artery.

\section{Techniques}

In 8 procedures, a double-lumen Scepter XC catheter balloon was used for balloon-then-stent-assisted coiling. In this setting, following balloon-assisted coiling, an LBS was navigated through the Scepter XC catheter balloon and deployed in the branch on which the aneurysm was implanted. In 3 cases, an LBS was used to perform dual-stent configurations. In 18 cases, an LBS was used via a single-stent-placement assisted-coiling technique. In all these cases, the LBS was navigated and deployed across the aneurysm neck via a 0.0165 -inch microcatheter. The aneurysm coiling was performed through a 0.0165 -inch microcatheter previously jailed in the aneurysmal sac.

\section{Intraprocedural Adverse Events}

Five intraprocedural adverse events occurred in our series. In 3 cases (patients 1, 4, and 10), a partial intrastent thrombosis was noted after stent deployment. All these patients were good responders to clopidogrel. In all cases, the complication was managed by intravenous injection of glycoprotein IIb/IIIa (abciximab) and patients had no clinical consequences. In 2 cases, the deployment of the stent was not adequate (patients 7 and 14). The first event happened during the treatment of a ruptured right A1 blister aneurysm for which telescopic deployment of 2 LBSs was planned. The apposition of the 2 devices was not optimal, and the distal portion of the proximal stent did not expand correctly (Fig 2). An angiographic examination at 24 hours demonstrated A1 thrombosis. The second technical complication occurred during the retreatment of an AcomA aneurysm (patient 14). Following stent detachment, the operator was not able to recover the delivery wire because it was locked through the stent struts. Further attempts resulted in migration of the LBS into the right A1. Following this, the operator managed to recover the delivery wire but the stent had partially collapsed and was left in the A1. Despite several attempts to retrieve the LBS with an Amplatz goose neck snare (Covidien, Irvine, California), the stent was not recovered and the artery thrombosed. Both patients developed right ACA territory ischemia and subsequently died because of diffuse cerebral vasospasm.

\section{Immediate and Midterm Anatomic and Clinical Results}

Angiography performed at the end of the procedure showed complete aneurysm occlusion in 16 of 29 patients (55\%). Residual neck was recorded in 8 patients (27\%), and residual aneurysms, in 3 patients (10\%). In the remaining 2 patients, the aneurysm thrombosed with the parent artery intraprocedurally.

Twenty-seven patients of 29 (93\%) had midterm radiologic and clinical follow-up, and 2 patients died. Eleven patients had MR imaging follow-up between 6 and 14 months (median, 7 months), and 16 patients had DSA follow-up between 3 and 25 months (median, 12 months) after the treatment (Fig 3). Radiologic follow-up demonstrated complete aneurysm occlusion for 26 of 27 patients (96\%). In only 1 case (patient 3 ) did the 14 month MR imaging follow-up show a persisting residual aneurysm. All patients underwent clinical assessment at the time of the radiologic follow-up. Clinical outcome was assessed by a senior neurologist by using the mRS. In all patients followed up, an mRS $\leq 2$ was recorded.

\section{Flow-Diverter Effect}

In 1 case of an AcomA residual aneurysm (patient 17), in which following the detachment of the first coil, there was premature expulsion of the jailed microcatheter, the 9-month angiogram showed complete aneurysm occlusion. In 2 cases of A1 fusiform aneurysms (patients 5 and 29), immediate contrast media stagnation was visualized before the coiling and just after stent deployment. In both of these cases, the final postoperative angiogram showed residual aneurysms. The radiologic follow-up of both patients (DSA at 13 months and MR imaging at 6 months, respectively) showed remodelling of the parent artery and complete healing of the aneurysm. In 1 patient (patient 2) presenting with mass effect symptoms due to a large, partially thrombosed, basilar tip aneurysm, an LBS was deployed across the aneurysm neck after complete aneurysm coiling. The 8-month DSA showed complete aneurysm exclusion, and the 15-month MR imaging follow-up showed aneurysm shrinkage with considerable mass effect reduction. Clinical outcome was favorable, with resolution of the mass-related symptoms.

\section{In-Stent Neointimal Growth}

In 3 cases, angiography demonstrated neointimal in-stent growth within the stented artery. In 1 case, this neointimal hyperplasia was associated with reduction of the caliber of the origin of a collateral branch covered by the LBS (patient 28, Fig 4). In 1 case of an MCA aneurysm in which both bifurcation branches were stented (patient 6), angiography showed complete occlusion of the inferior branch. None of these angiographic findings were associated with any documented clinical symptoms.

\section{DISCUSSION}

The endovascular treatment results of wide-neck and complex aneurysms improved following the introduction of the balloonand stent-assisted coiling techniques. ${ }^{1-6}$ Remodelling balloons act as a temporary scaffold for coils positioned in aneurysms with unfavorable dome-to-neck ratios. Intracranial stents act as a permanent scaffold, which, to facilitate coiling, leads to moderate diversion of the blood flow out of the aneurysm sac toward the 



FIG 1. Patient 12. Retreatment of an ICA bifurcation aneurysm. A, A Neuroform EZ stent is initially deployed from the right MCA to the ipsilateral ICA then a 0.0165 -inch microcatheter is navigated in the right MCA via the AcomA from the left ICA. $B$ and C, An LBS is deployed within the right $\mathrm{Al}$, and additional coils are released into the aneurysm sac. $D$ and $E$, Postprocedural angiographic run.

vessel lumen and hence assists neck endothelialization due to neointima growth over the stent struts. ${ }^{7-12}$ A major limitation of "conventional" intracranial stents is that they must be delivered through "large-profile" 0.021 - or 0.027 -inch microcatheters. These represent a technical drawback, especially for the treatment of lesions with complex angioarchitecture or distal locations. Moreover, conventional stents, especially laser-cut stents, are prone to kinking and do not adequately conform to the parent artery. ${ }^{13}$ The LBS, with its technical features, represents an evolution in intracranial stents. The low profile of this device differentiates it from other conventional intracranial stents. The LBS can be navigated and delivered through standard-coiling 0.0165-inch microcatheters and dual-lumen balloon catheters. Consequently, it can be deployed in distal and tortuous vessel anatomy not achievable with conventional 0.021 - or 0.027 inch stent-delivery microcatheters. Furthermore, it can be navigated through relatively small AcomAs, and this feature allows a contralateral approach for the treatment of aneurysms for which an ipsilateral approach is not feasible or effective. In addition, it can be easily navigated and deployed through another intracranial stent to perform dual-stent-assisted coiling, especially the open-cell type.

Nevertheless, the LBS can be deployed within arteries with a diameter of $<2 \mathrm{~mm}$, such as the posterior inferior cerebellar artery or callosomarginal artery. Finally, its 16 braided filaments aid the optimal artery wall apposition and conformability of the de- vice to the arterial anatomy. ${ }^{14}$ The LBS cell size is approximately $0.9 \mathrm{~mm}$, and when it is released, the cells are usually compressed due to the advancement of the device, performed by the operator, over the delivery wire while the delivery catheter is maintained in a fixed position. The consequence of this delivery technique is that along the neck the cells size is reduced and the metal coverage increases. ${ }^{15}$ Also, the hemodynamic deflection across the neck segment is higher in comparison with conventional laser-cut stents. ${ }^{16}$ This feature probably explains the flow-diverter-like effect that we noted in some cases in our series, along with the extremely high rate of complete aneurysm occlusion reported at the midterm radiologic follow-up (26 of 27 patients, 96\%).

\section{Balloon-Then-Stent-Assisted Coiling Technique}

Spiotta et a ${ }^{17}$ first described the balloon-then-stent-assisted coiling technique. This procedure incorporates the use of a coaxial dual-lumen balloon catheter system (Scepter XC) through which a microstent, an LVIS Junior (MicroVention) in the original report, is advanced and delivered following aneurysm balloon-assisted coiling. This strategy is performed to add the benefits of the remodeling technique, such as better control of the microcatheter positioning and increasing packing density, to the benefits of the parent artery stent placement. The single-access technique for balloon-then-stent-assisted coiling was performed in 8 patients in our series by using the Scepter XC balloon first and then the LBS. 

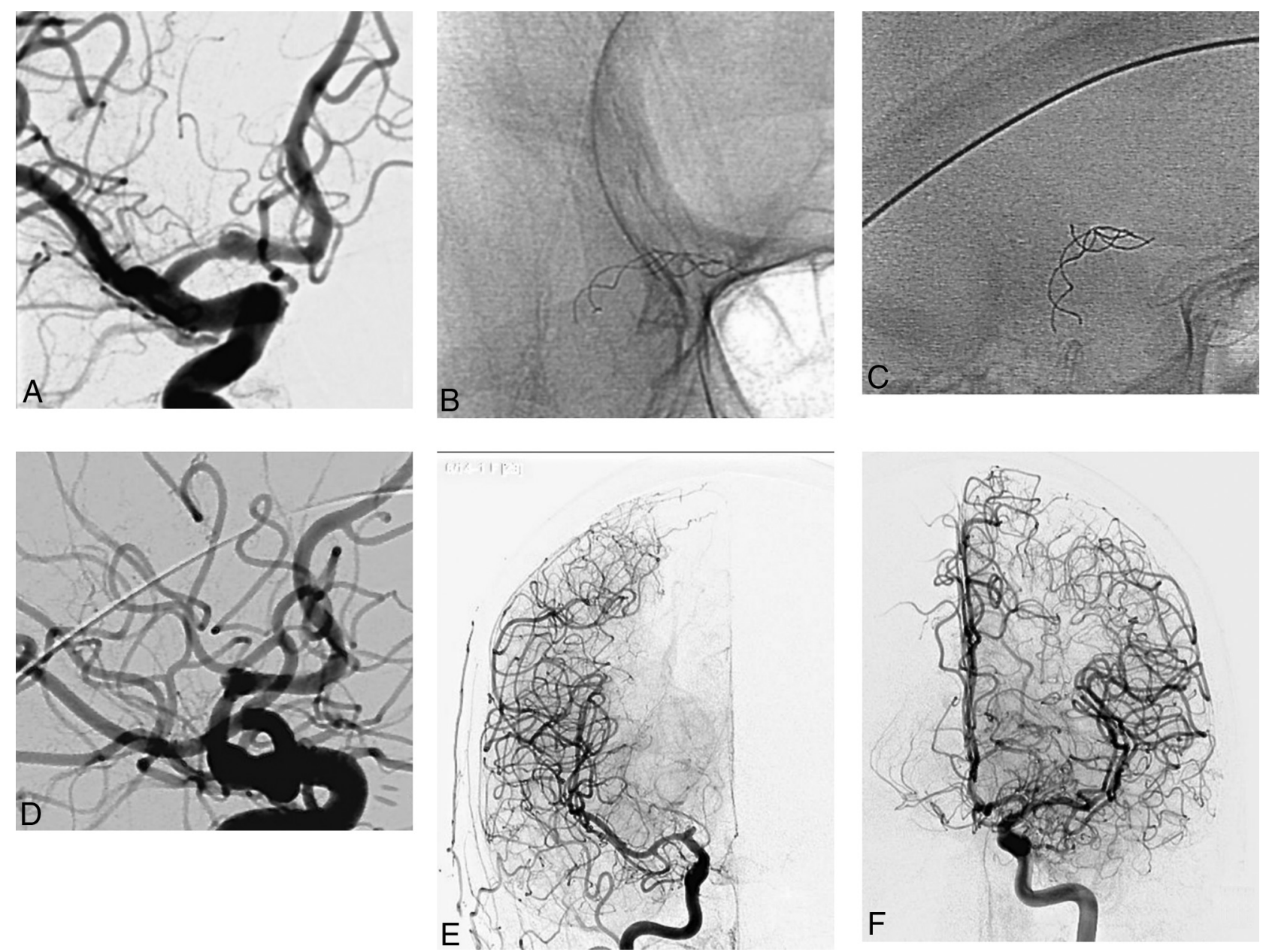

FIG 2. Patient 7. A, A ruptured Al blister aneurysm. $B$ and $C, A$ nonoptimal apposition of telescoped LBSs (right oblique view). D, Postprocedural DSA. $E$ and $F$, Angiograms obtained the day following the intervention show complete Al occlusion.

No technical complications were recorded among these procedures, and the midterm radiologic follow-up showed complete aneurysm occlusion for all these aneurysms except for 1 for which a 3-mm residual neck was noted. To our knowledge, the use of the LBS single-access technique for balloon-then-stent-assisted coiling has not been reported in the literature.

\section{LBS Used For Dual-Stent-Assisted Coiling}

Akmangit et al ${ }^{18}$ recently reported a series of 12 patients treated with the LBS used in a dual-stent configuration for the treatment of wide-neck, complex, and distal intracranial aneurysms. Nine patients from this series were treated with dual-stent-assisted coiling with 2 LBSs deployed in Y-, X-, and T-configurations, while 3 patients were treated with 2 telescoped LBSs without adjunctive coiling. Similar to findings in our series, good results in terms of technical feasibility and clinical and anatomic outcome were reported. In our series, 4 patients were treated with a dual-stent configuration. In 2 cases, an LBS was used in a dual-stent configuration with a Neuroform EZ stent. The Neuroform EZ stent is an open-cell laser-cut autoexpandable nitinol stent, which is delivered through a 0.027 -inch microcatheter system. The Neuroform EZ stent was used with an LBS in 1 case of an MCA aneurysm for a Y-stent-assisted coiling and in 1 case of A1 T-stent-assisted coiling.
The rationale for the use of an open-cell stent is that when it is first placed in one of the bifurcation branches (in cases of bifurcation aneurysms), the catheterization of the other bifurcation branch through its open cells with a 0.0165 -inch microcathter is relatively easy. Furthermore, the intersection between a low-profile stent and an open-cell stent reduces, theoretically, the risk of obstruction of the second stent at the point of intersection with the first one. In this setting, both stents provide a scaffold for aneurysm coiling and branch protection; moreover, the LBS provides a flow-diverter-like effect from the aneurysm toward the parent vessel. It could be argued that the intersection between 2 intracranial stents in a Y-configuration is suitable for intra-aneurysmal flow disruption and that it is not related to a higher rate of thromboembolic complications. ${ }^{19-21}$ Nevertheless, long-term results of patients treated with such Y-intersecting stents are lacking, and our experience demonstrates that a novel nonintersecting dualstent $\mathrm{Y}$-configuration is feasible by using the LBS in combination with the Neuroform EZ stent. To our knowledge, this configuration has not been reported.

\section{Intraprocedural Complications}

Five intraoperative complications occurred in our series (5 of 29, 17\%); in 3 cases, an intrastent thrombus formation was noted 

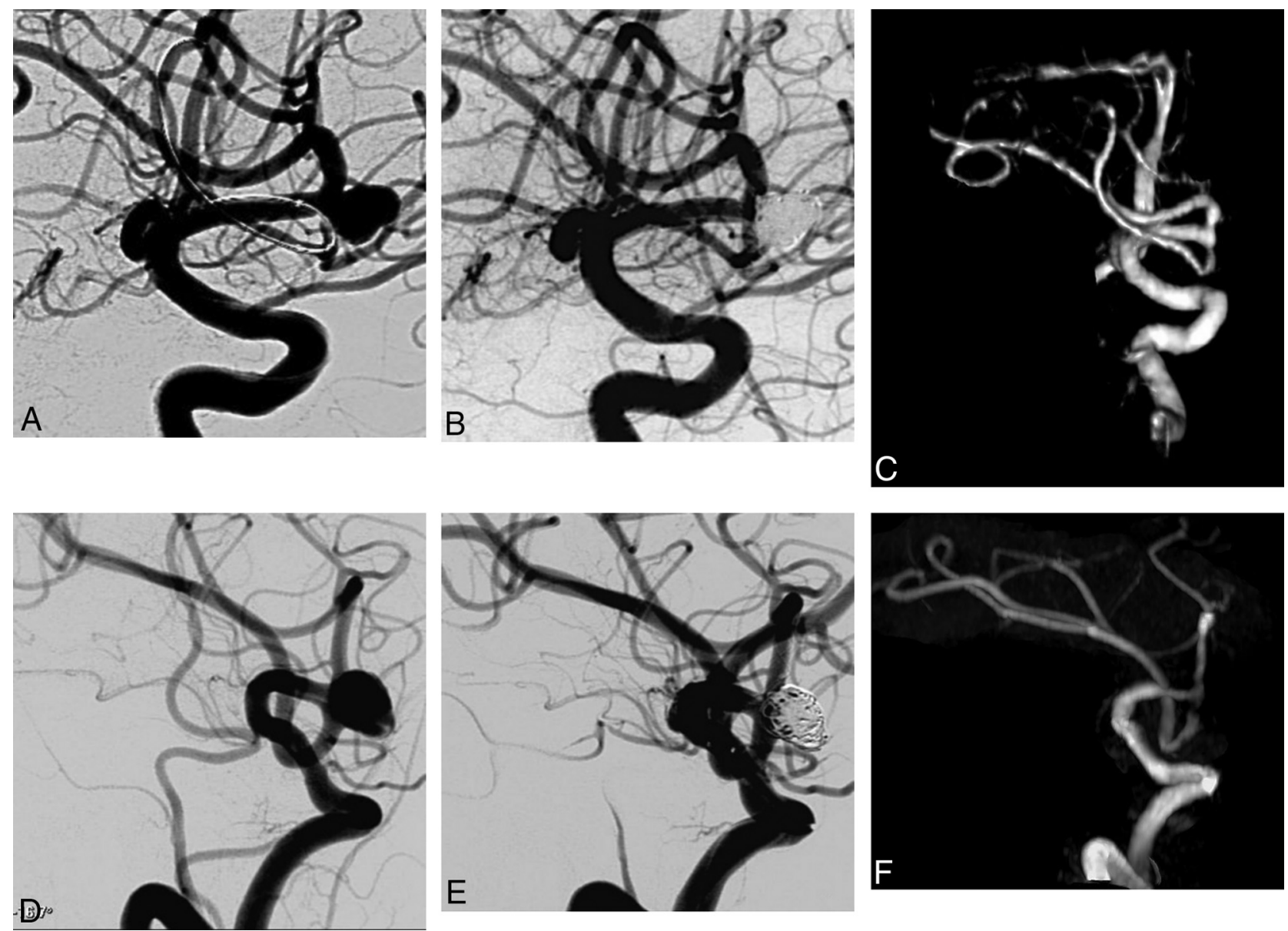

FIG 3. Two examples $(A-C, D-F)$ of $M C A$ aneurysms followed by MR imaging time-of-flight angiography.
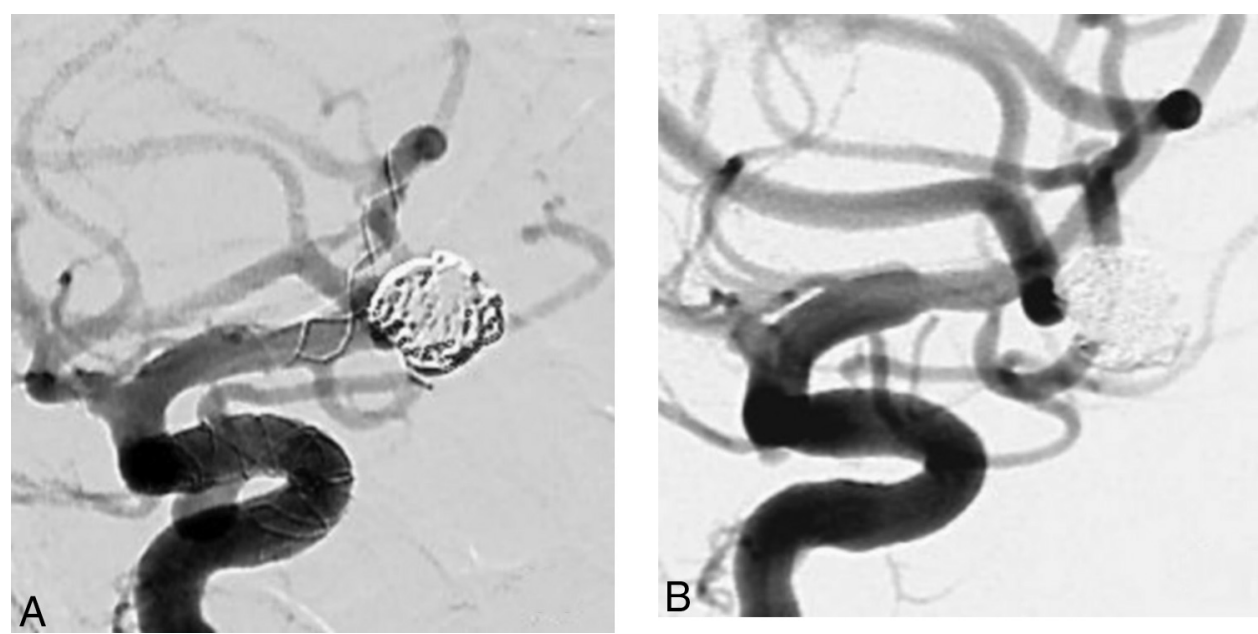

FIG 4. Patient 28. A, Postprocedural DSA of an MCA aneurysm treated with an LBS (in the same session the patient was treated for an ipsilateral carotid-cave aneurysm with a Silk flow-diverter [Balt Extrusion]). B. The DSA midterm follow-up shows shrinkage of the stented artery and of the origin of the MCA branch covered by the LBS.

after LBS deployment. The complication was managed with intravenous injection of glycoprotein IIb/IIIa (abciximab), and all patients had a good clinical outcome. In 2 of the transient thrombotic cases (patients 1 and 11), retrospective analysis of the nonsubtracted angiograms obtained after stent placement showed suboptimal deployment of the device. The radiopaque struts of the stents appeared elongated and not fully expanded. This non- complete expansion of the stent probably led to turbulent blood flow within the device and subsequently platelet aggregation. In 2 cases, we recorded an intraprocedural technical complication: The first was a case of dual-telescopic stent configuration in which the apposition of the devices was not adequate and led to alteration of the laminar blood flow and to acute thrombosis of the parent vessel. The second was a case in which after LBS deploy- 
ment, the operator was not able to recover the delivery wire because it was caught by the stent struts; additional attempts of delivery wire retrieval resulted in migration and collapse of the device. In these cases, the LBS was responsible for parent artery occlusion and IV abciximab was not effective in artery reopening. Both patients developed parenchymal ischemia in the territory of the stented artery and thereafter died because of diffuse cerebral vasospasm (these patients were in the acute and subacute phase of subarachnoid hemorrhage).

These deaths were taken into account for the mortality rate of our series $(2 / 29,6.8 \%)$. Therefore, the permanent morbidity and the mortality rates of our series were $0 \%$ and $6.8 \%$, respectively. In 3 of 5 cases of complications in our series, the probable cause was related to the nonoptimal deployment of the device. It is unclear whether this was due to inappropriate maneuvering of the operator or the behavior of the stent itself. The LBS seems to have a moderate tendency to shorten after deployment. On the other hand, the higher "metal-to-artery" ratio of the braided stents in comparison with laser-cut stents, especially when placed in lowdiameter arteries, might be related to a higher incidence of acute intrastent thrombus formations. Turk et $\mathrm{al}^{22}$ reported a series of 8 distal aneurysms treated by stent-assisted coiling by using the Neuroform stent. The authors reported 2 intraprocedural thrombotic events, which were successfully treated by IV injection of abciximab. The incidence of intraprocedural thrombotic complications in this series ( 2 of $8,25 \%)$ seems to be higher in comparison with our results.

\section{LVIS Junior Stent}

In a recent publication, Behme et $\mathrm{al}^{23}$ reported their experience in using the LVIS Junior (MicroVention) stent for the treatment of 32 patients with 34 aneurysms. The LVIS Junior is an intracranial self-expandable stent made of 12 braided nitinol wires with technical features similar to those of the LBS. Similar to findings in our report, 5 complications occurred in this series, and 2 were related to intrastent periprocedural thrombosis. In both cases, patients were treated with intravenous eptifibatide and had a good clinical outcome. No information about stent deployment or opening is available in these patients. The anatomic results of this series are also similar to those in our study, with a rate of complete aneurysm occlusion at the midterm follow-up of $>90 \%$. Möhlenbruch et $\mathrm{al}^{24}$ reported the results of a series of 22 patients treated with LVIS Junior-assisted coiling. In this cohort, 3 cases of partial, nonocclusive in-stent thrombosis occurred. All these complications completely resolved after intravenous injection of tirofiban. The authors reported no mortality or new neurologic deficits assessed in the periprocedural period or at the midterm follow-up in any patient in this series. Even for this cohort of patients, the midterm radiologic follow-up showed a rate of complete aneurysm occlusion of $90 \%$.

\section{Conventional Intracranial Stents and Thrombotic Complications}

In our series, we recorded an extremely high radiologic rate of complete aneurysm cure at the midterm follow-up. Nevertheless, we experienced an intrastent thrombotic complication in 5 cases (of $29,17 \%$ ), and even if this led to the death of 2 patients ( 2 of 29 ,
$6.8 \%$ ), we have to compare these data with those reported in the literature on conventional stents. Bodily et $\mathrm{al}^{25}$ reported a metaanalysis of 339 ruptured aneurysms treated by stent-assisted coiling with different types of laser-cut stents during the acute phase after rupture. The rate of clinically relevant thromboembolic complications in this series was $6 \%$, while the incidence of clinically relevant hemorrhagic complications was $8 \%$. The authors concluded that thromboembolic complications appeared reasonably well-controlled. Hetts et $\mathrm{al}^{26}$ compared the results of a series of 361 patients treated for an unruptured aneurysm with stentassisted coiling (performed with laser-cut stents) or simple coiling; 137 patients in this series (of 361, 38\%) underwent stent placement. At 1 year, total significant adverse events, mortality and morbidity, were similar in both groups, but ischemic strokes were more common in patients with stent-assisted coiling than in those with simple coiling, $8.8 \%$ versus $2.2 \%$. The authors concluded that patients in both groups had similar outcomes, and the increased ischemic events in stent-coiled aneurysms were attributable to baseline risk factors and aneurysm morphology.

Luo et $\mathrm{al}^{11}$ reported results of a series of 15 patients with 17 aneurysms treated with LEO stents. Similar to findings in our series, the authors reported 2 cases of technical complications and 2 cases of periprocedural thromboembolic complications. Lv et $\mathrm{al}^{27}$ reported a series of 28 patients treated with coiling assisted by LEO stents. The authors reported 3 (of 28, 10.7\%) asymptomatic parent artery occlusions related to the deployment of the stent and 1 stent migration. Given the above results, the rate of thrombotic complications recorded with the LBS seems to be quite comparable with the rate reported in other conventional intracranial stents. Occurrence of thromboembolic complications after stent placement is the most frequent adverse event reported in the literature and in our series. In 3 of 4 thrombotic complications recorded in our series, an inadequate deployment of the stent was noted. In our opinion, the incidence of this type of complication is directly related, beyond the responsiveness of the patient to antiplatelet drugs, to the quality of the deployment of the device, hence its opening and apposition to the vessel wall. Incomplete or inadequate opening of the device is a potential cause of laminar blood flow alteration and thrombus formation.

\section{CONCLUSIONS}

The results obtained in our study by using the LBS for balloonthen-stent and single- or dual-stent-assisted coiling of complex and distally located intracranial aneurysms are encouraging. Due to its technical features, this device allows the treatment of lesions with complex angioarchitecture, not accessible with standard 0.021- or 0.027-inch microcatheters. Furthermore, we noted that the LBS may have some flow-diverter-like properties that can lead to aneurysm cure even after partial or incomplete coiling. The results of our study should be compared with those in larger series and long-term clinical outcome data.

Disclosures: Vincent Costalat-UNRELATED: Consultancy: Sequent Medical, Covidien, Stryker, Balt Extrusion; Payment for Lectures (including service on Speakers Bureaus): Covidien, Stryker, Sequent Medical; Payment for Development of Educational Presentations: Covidien, Stryker. Alain Bonafé-UNRELATED: Consultancy: Covidien, Stryker. 


\section{REFERENCES}

1. Moret J, Cognard C, Weill A, et al. The "remodeling technique" in the treatment of wide neck intracranial aneurysms: angiographic results and clinical follow-up in $\mathbf{5 6}$ cases. Interv Neuroradiol 1997;3: 21-35 Medline

2. Shapiro M, Babb J, Becske T, et al. Safety and efficacy of adjunctive balloon remodeling during endovascular treatment of intracranial aneurysm: a literature review. AJNR Am J Neuroradiol 2008;29: 1777-81 CrossRef Medline

3. Pierot L, Cognard C, Spelle L, et al. Safety and efficacy of balloon remodelling technique during endovascular treatment of intracranial aneurysms: critical review of the literature. AJNR Am J Neuroradiol 2012;33:12-15 CrossRef Medline

4. Piotin M, Blanc R, Spelle L, et al. Stent-assisted coiling of intracranial aneurysms: clinical and angiographic results in 216 consecutive aneurysms. Stroke 2010;41:110-15 CrossRef Medline

5. Vendrell JF, Costalat V, Brunel H, et al. Stent-assisted coiling of complex middle cerebral artery aneurysms: initial and midterm results. AJNR Am J Neuroradiol 2011;32:259-63 CrossRef Medline

6. Biondi A, Janardhan V, Katz JM, et al. Neuroform stent-assisted coil embolization of wide-necked intracranial aneurysms: strategies in stent deployment and midterm follow-up. Neurosurgery 2007;61: 460-68; discussion 468-69 Medline

7. Machi P, Lobotesis K, Vendrell JF, et al. Endovascular therapeutic strategies in ruptured intracranial aneurysms. Eur J Radiol 2013;82: 1646-52 CrossRef Medline

8. Fiorella D, Albuquerque FC, Deshmukh VR, et al. Endovascular reconstruction with the Neuroform stent as monotherapy for the treatment of uncoilable intradural pseudoaneurysms. Neurosurgery 2006;59:291-300; discussion 299-300 Medline

9. Kono K, Terada T. Hemodynamics of $\mathbf{8}$ different configurations of stenting for bifurcation aneurysms. AJNR Am J Neuroradiol 2013; 34:1980 - 86 CrossRef Medline

10. Lee YJ, Kim DJ, Suh SH, et al. Stent-assisted coil embolization of intracranial wide-necked aneurysms. Neuroradiology 2005;47: 680-89 CrossRef Medline

11. Luo J, Lv X, Jiang C, et al. Preliminary use of the Leo stent in the endovascular treatment of wide-necked cerebral aneurysms. World Neurosurg 2010;73:379-84 CrossRef Medline

12. Bendok BR, Parkinson RJ, Hage ZA, et al. The effect of vascular reconstruction device-assisted coiling on packing density, effective neck coverage, and angiographic outcome: an in vitro study. Neurosurgery 2007;61:835-40; discussion 840-41 Medline

13. Krischek O, Miloslavski E, Fischer S, et al. A comparison of functional and physical properties of self-expanding intracranial stents [Neuroform3, Wingspan, Solitaire, Leo+, Enterprise]. Minim Invasive Neurosurg 2011;54:21-28 CrossRef Medline

14. Valdivia Y, Alvarado M, Ebrahimi N, et al. Study of conformability of the new Leo plus stent to a curved vascular model using flat-panel detector computed tomography (DynaCT). Neurosurgery 2009;64 (3 suppl):ons130-34; discussion ons134 Medline

15. Aenis M, Stancampiano AP, Wakhloo AK, et al. Modeling of flow in a straight stented and nonstented side wall aneurysm model. J Biomech Eng 1997;119:206-12 CrossRef Medline

16. Pumar JM, Lete I, Pardo MI, et al. LEO stent monotherapy for the endovascular reconstruction of fusiform aneurysms of the middle cerebral artery. AJNR Am J Neuroradiol 2008;29:1775-76 CrossRef Medline

17. Spiotta AM, Miranpuri A, Chaudry MI, et al. Combined balloon stent technique with the Scepter C balloon and low-profile visualized intraluminal stent for the treatment of intracranial aneurysms. J Neurointerv Surg 2013;5(suppl 3):iii79-82 CrossRef Medline

18. Akmangit I, Aydin K, Sencer S, et al. Dual stenting using low profile LEO Baby stents for the endovascular management of challenging intracranial aneurysms. AJNR Am J Neuroradiol 2015;36:323-29 CrossRef Medline

19. Spiotta AM, Gupta R, Fiorella D, et al. Mid-term results of endovascular coiling of wide-necked aneurysms using double stents in a $\mathrm{Y}$ configuration. Neurosurgery 2011;69:421-29 CrossRef Medline

20. Thorell WE, Chow MM, Woo HH, et al. Y-configured dual intracranial stent-assisted coil embolization for the treatment of widenecked basilar tip aneurysms. Neurosurgery 2005;56:1035-40; discussion 1035-40 Medline

21. Fargen KM, Mocco J, Neal D, et al. A multicenter study of stentassisted coiling of cerebral aneurysms with a $\mathrm{Y}$ configuration. $\mathrm{Neu}$ rosurgery 2013;73:466-72 CrossRef Medline

22. Turk AS, Niemann DB, Ahmed A, et al. Use of self-expanding stents in distal small cerebral vessels. AJNR Am J Neuroradiol. 2007;28: 533-36 Medline

23. Behme D, Weber A, Kowoli A, et al. Low-profile Visualized Intraluminal Support device (LVIS Jr) as a novel tool in the treatment of wide-necked intracranial aneurysms: initial experience in 32 cases. J Neurointerv Surg 2015;7:281-85 CrossRef Medline

24. Möhlenbruch M, Herweh C, Behrens L, et al. The LVIS Jr. microstent to assist coil embolization of wide-neck intracranial aneurysms: clinical study to assess safety and efficacy. Neuroradiology 2014;56: 389-95 CrossRef Medline

25. Bodily KD, Cloft HJ, Lanzino G et Al. Stent-assisted coiling in acutely ruptured intracranial aneurysms: a qualitative, systematic review of the literature. AJNR Am J Neuroradiol 2011;32:1232-36 CrossRef Medline

26. Hetts SW, Turk A, English JD, et al; Matrix and Platinum Science Trial Investigators. Stent-assisted coiling versus coiling alone in unruptured intracranial aneurysms in the Matrix and Platinum Science Trial: safety, efficacy, and mid-term outcomes. AJNR Am J Neuroradiol 2014;35:698-705 CrossRef Medline

27. Lv X1, Li Y, Jiang C et al. Potential advantages and limitations of the Leo stent in endovascular treatment of complex cerebral aneurysms. Eur J Radiol 2011;79:317-22 CrossRef Medline 